\title{
LETTER
}

\section{Rhenium in seawater: Confirmation of generally conservative behavior}

\author{
A. D. Anbar, R. A. Creaser,* D. A. Papanastassiou, and G. J. WasserburG \\ The Lunatic Asylum of the Charles Arms Laboratory, Division of Geological and Planetary Sciences, \\ California Institute of Technology, Pasadena, CA 91125 , USA
}

(Received May 12, 1992; accepted in revised form August 25, 1992)

\begin{abstract}
A depth profile of the concentration of Re was measured in the Pacific Ocean using a technique we have developed for the clean chemical separation and the precise measurement of $\operatorname{Re}$ by isotope dilution and negative thermal ionization mass spectrometry (ID-NTIMS). This technique permits Re concentrations to be determined from $200 \mathrm{~mL}$ of seawater with a typical precision of $\pm 5 \%$. This is an improvement of at least a factor of 100 over the techniques used in previously published determinations of $R e$ in seawater. We obtain a narrow range for $\operatorname{Re}$ from $7.20 \pm 0.03$ to $7.38 \pm 0.03 \mathrm{ng} / \mathrm{kg}$ for depths between $45 \mathrm{~m}$ and $4700 \mathrm{~m}$. This demonstrates that $R e$ is relatively well mixed throughout the water column and confirms the theoretical prediction that the behavior of $\mathrm{Re}$ in the oceans is conservative. When examined in detail, both salinity and the concentration of Re increase by approximately $1.5 \%$ between 400 and $4700 \mathrm{~m}$, a correlation consistent with conservative behavior. However, $\operatorname{Re}$ appears to be depleted relative to salinity by $1.0-1.5 \%$ at $100 \mathrm{~m}$, and enriched by approximately $4 \%$ at the surface. These observations suggest a minor level of Re scavenging in near surface waters, and an input of Re to the ocean surface. This work demonstrates the utility of ID-NTIMS for geochemical investigations of certain trace elements that have not previously been amenable to detailed study.
\end{abstract}

\section{INTRODUCTION}

THE GEOCHEMISTRY OF the Platinum Group Elements (PGE) and their periodic table neighbors is poorly understood, despite increasing interest in recent years in the use of these elements as isotopic and elemental tracers, and for geochronometry. This problem is particularly acute in the marine environment, where the surface abundances of $\mathrm{Os}, \mathrm{Ir}, \mathrm{Ru}$, and $\mathrm{Rh}$ are poorly constrained, and their depth profiles are unknown. Depth profiles have been measured for $\mathrm{Pt}, \mathrm{Pd}$, and Re (e.g., Pt: GOLdBerg et al., 1986; JACINTO and VAN DEN BERG, 1989; Pd: LEE, 1983; Re: MATTHEWS and RILEY, 1970; OLAFSSON and RIIEY, 1972; KOIDE et al., 1987), but these data have raised as many questions as they have answered. For example, the studies of the marine distribution of $\mathrm{Pt}$ have each yielded a different trend with depth. The cause of these differences is undetermined.

Uncertainty has also surrounded the marine geochemistry of $\mathrm{Re}$. The concentration of $\mathrm{Re}$ in oxygenated seawater is expected to be fairly uniform with depth, as the stable form of $\mathrm{Re}$ in these waters should be the perrhenate anion, $\mathrm{ReO}_{4}^{-}$(BRULAND, 1983; BROOKINS, 1986). Thus, the behavior of $\mathrm{Re}$ should be conservative in seawater. This expectation is consistent with the apparent enrichment of $\mathrm{Re}$ in seawater relative to its periodic table neighbors (KOIDE et al., 1987), which suggests that $\operatorname{Re}$ has an extremely long residence time in the oceans (GOLDBERG et al., 1988). However, the published measurements of the concentration of rhenium

* Present address: Department of Geology, University of Alberta, 1-26 Earth Sciences Building, Edmonton, Alberta, Canada T6G $2 \mathrm{E} 3$. in seawater indicate a range of approximately 3 to $11 \mathrm{ng} / \mathrm{kg}$ (SCADDEN, 1969; OLAFSSON and RILEY, 1972; MATTHEWS and RILEY, 1970; KOIDE et al., 1987). These variations probably reveal a lack of precision and sensitivity in the analytical methods used, so that the content of Re in seawater is determined by these data to no better than a factor of three.

Our understanding of the geochemistry of Re and the PGE is limited largely by their low abundances and, until recently, the lack of analytical techniques which are sensitive, precise, and accurate enough to obtain reliable abundance measurements. The application of NTIMS to these elements (ZEININGER, 1984; DELMORE, 1987; HEUMANN, 1988; VOLKENING et al., 1991; CREASER et al., 1991) introduced a highly sensitive new tool for their study. In order to resolve the problem of the Re concentration of seawater and its distribution with depth, we have applied ID-NTIMS to the study of $R e$ in a Pacific Ocean profile.

\section{SAMPLING AND ANALYSIS}

Seawater samples were collected in January 1992, on the HOT33 cruise (R/V Wecoma) at Station Aloha, approximately $100 \mathrm{~km}$ north of Oahu $\left(22^{\circ} \mathrm{N}, 158^{\circ} \mathrm{W}\right)$. Nine samples were collected using PVC Niskin bottles with Teflon-coated internal springs, lowered on a steel cable. One sample (at $45 \mathrm{~m}$ ) was collected using a Go-Flo bottle on a Kevlar line. Pressure, temperature, conductivity, and dissolved oxygen were monitored continuously using a conductivity. temperature-depth probe (CTD) and an oxygen sensor (KARL and WINN, 1991). The depth, salinity, and oxygen data reported in this study were derived from the CTD and oxygen sensor data (Table 1; D. Karl and R. Lukas, pers. commun.). After recovery, all samples were filtered within $48 \mathrm{~h}$ through $0.2 \mu \mathrm{m}$ nitrocellulose filters using a peristaltic pump, then acidified by adding $2 \mathrm{~mL}$ of $12 \mathrm{~N} \mathrm{HCl}$ to each liter of seawater, and stored in acid-washed high density polyethylene bottles for later analysis. 
TABLE 1. Re concentrations in the Pacific Ocean

\begin{tabular}{|c|c|c|c|c|c|}
\hline $\begin{array}{c}\text { Sample } \\
\text { Depth (m) }\end{array}$ & $\begin{array}{c}\mathrm{Re} \\
\text { (ng/kg) }\end{array}$ & $\begin{array}{c}\operatorname{ReN}_{(\mathrm{ng}} \\
(\mathrm{ng} / \mathrm{kg})\end{array}$ & 20 & $\begin{array}{c}\text { Salinity } \\
(\%)\end{array}$ & $\begin{array}{c}\text { Oxygen } \\
\text { (umol/kg) }\end{array}$ \\
\hline $\begin{array}{c}6(\mathrm{a}) \\
45^{(b)} \\
51 \\
100 \\
402(\mathrm{a}) \\
\text { (b) } \\
749 \\
1499 \\
2198 \\
2800(\mathrm{a}) \\
4705^{(\mathrm{b})}\end{array}$ & $\begin{array}{l}7.70 \\
7.68 \\
7.38 \\
7.35 \\
7.34 \\
7.20 \\
7.24 \\
7.30 \\
7.31 \\
7.32 \\
7.34 \\
7.36 \\
7.34\end{array}$ & $\begin{array}{l}7.70 \\
7.68 \\
7.35 \\
7.33 \\
7.39 \\
7.43 \\
7.44 \\
7.40 \\
7.40 \\
7.41 \\
7.44 \\
7.41\end{array}$ & $\begin{array}{l}0.07 \\
0.06 \\
0.03 \\
0.03 \\
0.03 \\
0.03 \\
0.04 \\
0.03 \\
0.03 \\
0.03 \\
0.06 \\
0.03 \\
0.03\end{array}$ & $\begin{array}{l}35.006 \\
35.089 \\
34.104 \\
34.354 \\
34.561 \\
34.622 \\
34.653 \\
34.645\end{array}$ & $\begin{array}{rr}2 & 205.4 \\
& \\
6 & 205.4 \\
9 & 205.4 \\
4 & 156.3 \\
4 & \\
4 & 26.8 \\
1 & 62.5 \\
2 & 84.8 \\
3 & 111.6 \\
5 & 138.4\end{array}$ \\
\hline
\end{tabular}

ReN is the Re concentration normalized to $35 \%$ salinity. The uncertainty of each measurement is derived from uncertainties in the measured $249 / 251$ ratio, tracer concentration, and all gravimetric determinations, (see text) Replicate samples $(6,402$ and $2800 \mathrm{~m}$ ) were processed separately, and indicate that the analytical variability was within the uncertainties of the individual measurem was Samples 6 (a), (b) and 2800 (b) were spiked using the Dil2 tracer. All other samples were spiked with Dil-1.

Accurately weighed $200 \mathrm{~mL}$ fractions from all samples, except for the $6 \mathrm{~m}$ sample, were spiked with a ${ }^{185}$ Re-enriched tracer solution approximately 3 months after collection. The 6-m sample was spiked aboard ship, following filtration and acidification. In all spiked solutions, the measured ${ }^{185} \mathrm{Re} /{ }^{187} \mathrm{Re}$ ratio was close to the optimal value needed to minimize the error propagation factor. After the addition of the tracer, the solutions were periodically shaken and stirred over $24-48 \mathrm{~h}$, which was deemed sufficient time for complete equilibration of the $R e$ isotopes, since $R e$ is presumed to be present as $\mathrm{ReO}_{4}^{-}$in both samples and tracer. The $\mathrm{Re}$ tracer was prepared by dissolving ${ }^{185}$ Re-enriched metal (Oak Ridge National Laboratory) in $16 \mathrm{~N} \mathrm{HNO}_{3}$ and diluting to $1 \mathrm{~N}$ with ultrapure water. Two dilutions of this stock solution were prepared. Dilution 1 (Dil-1) was used to spike the $6 \mathrm{~m}$ sample aboard ship, and a $2800 \mathrm{~m}$ fraction in the lab. Dilution 2 (Dil-2) was used for the other samples spiked in the laboratory. The concentration of ${ }^{185} \mathrm{Re}$ in both of these tracer solutions was determined by calibration against a gravimetrically prepared standard solution of isotopically normal, high purity Re metal (Johnson Matthey). The isotopic composition of the tracer solutions was determined by NTIMS in our laboratory $\left({ }^{185} \mathrm{Re} /{ }^{187} \mathrm{Re}=37.14\right.$ \pm 0.04 ), and the isotopic composition of the standard solutions and natural samples is assumed to be ${ }^{185} \mathrm{Re} /{ }^{187} \mathrm{Re}=0.5974 \pm 0.0004$ (GRAMLICH et al., 1973). The isotopic composition of Re standard solutions determined by NTIMS in our laboratory $(0.5976 \pm 0.0003)$ is identical to the isotopic abundance ratio determined by GRAMLICH et al. (1973), using carefully controlled procedures.

Rhenium was separated from the seawater samples by anion exchange chromatography using two small Teflon columns (e.g., HuFFMAN et al., 1956). Primary separation utilized $200 \mu \mathrm{L}$ Bio-Rad AGI-X8, 100-200 mesh resin, onto which $\mathrm{ReO}_{4}^{-}$was adsorbed directly from the spiked, acidified seawater. The column was rinsed with 10 mL ultrapure $\mathrm{H}_{2} \mathrm{O}$, followed by $650 \mu \mathrm{L} 4 \mathrm{~N} \mathrm{HNO}_{3}$ to remove Mo and $\mathrm{W}$. These elements are both present as oxyanions in seawater at higher concentrations than Re. Rhenium was then eluted with $2 \mathrm{~mL}$ $4 \mathrm{~N} \mathrm{HNO}_{3}$. The resulting solution was evaporated to a small drop at $70-80^{\circ} \mathrm{C}$ under $\mathrm{N}_{2}$, and passed through a second column with 5$10 \mu \mathrm{L}$ of resin to purify $\mathrm{Re}$ further and to reduce the small amount of organic residue remaining from the first column. This entire separation procedure had a yield of $90 \%$, determined by isotope dilution analysis of a known amount of $\operatorname{Re}$ that was passed through the chemistry. The chemical blanks were in the range $2-5 \mathrm{pg}$. For all the data reported below, the quantity $3.5 \mathrm{pg}$ was subtracted from the quantity of sample Re that was determined to be present by isotope dilution analysis. Since approximately $1.5 \mathrm{ng}$ of $\mathrm{Re}$ was typically separated from the seawater aliquots, the resulting blank correction was less than $3 \%$ of the total sample Re present. This is smaller than the total uncertainty of the analytical procedure (see the following text).

The chemically separated Re was loaded using polyethylene tubing on a microsyringe, onto a high purity $\mathrm{Pt}$ filament on which $\mathrm{Ba}$ had been loaded as $\mathrm{BaSO}_{4}$ (used to enhance negative ion emission), and analyzed in a Lunatic mass spectrometer configured for negative ions (WASSERBURG et al., 1969; CrEASER et al., 1991). When prepared as a fine precipitate, $\mathrm{BaSO}_{4}$ forms an even coat on the filament, on which the sample may be easily loaded. The $\mathrm{BaSO}_{4}$ was found to provide a reproducible and efficient method of obtaining a higher ionization efficiency for both samples and standards than was possible using other $\mathrm{Ba}$ salts, such as $\mathrm{Ba}\left((\mathrm{NO})_{3}\right)_{2}$ or $\mathrm{Ba}(\mathrm{OH})_{2}$ (CREASER et al., 1991; HEUMANN, 1988). The ionization efficiency for Re standards was $20 \%$. The ionization efficiency was lower for separated samples due to the presence of organic material in the final load, and ranged from 1 to $10 \%$ for the samples analyzed in this study.

Re was analyzed as $\mathrm{ReO}_{4}^{-}$at masses 249 and 251 , and the ion intensity at 251 was corrected for the contribution from ${ }^{185} \mathrm{Re}^{16} \mathrm{O}_{3}{ }^{18} \mathrm{O}^{-}$ using ${ }^{18} \mathrm{O} /{ }^{16} \mathrm{O}=0.002085$ to obtain the ratio ${ }^{185} \mathrm{Re} /{ }^{187} \mathrm{Re}$. This ${ }^{18} \mathrm{O} /$ ${ }^{16} \mathrm{O}$ ratio has been measured directly for normal $\mathrm{Re}$, using the ${ }^{187} \mathrm{ReO}_{4}^{-}$ion beams (CREASER et al., 1991). The contribution from ${ }^{187} \mathrm{Re}^{17} \mathrm{O}_{2}{ }^{16} \mathrm{O}_{2}^{-}$at mass 251 is negligible. When running seawater samples, ion currents corresponding to $10^{7}-10^{8}$ counts per second (cps; $0.16-1.6 \times 10^{-11} \mathrm{~A}$ ) at masses 249 and 251 were routinely sustained for $30-40 \mathrm{~min}$ on a Faraday collector, at filament temperatures of $840-890^{\circ} \mathrm{C}$, as determined by an optical pyrometer.

To determine the level of the ion current due to background contamination, $\mathrm{BaSO}_{4}$ was loaded on a filament without any sample or tracer. Ion currents corresponding to $10^{3}-10^{4} \mathrm{cps}$ at mass 251 were measured over the temperature range $840-890^{\circ} \mathrm{C}$. This current increased with increasing filament temperature, but was fairly constant over time when the temperature was not varied. The ratio ${ }^{185} \mathrm{Re} /$ ${ }^{187} \mathrm{Re}$ measured in this experiment was indistinguishable from that of normal Re.

In order to establish the level of the filament blank under controlled conditions, we loaded $36 \mathrm{pg}$ of Re tracer on a Pt filament with $\mathrm{BaSO}_{4}$, and obtained a stable signal at mass 249 equivalent to $\approx 10^{6} \mathrm{cps}$, at a filament temperature of $850^{\circ} \mathrm{C}$. The initial ${ }^{185} \mathrm{Re} /{ }^{187} \mathrm{Re}$ measured was 33.4 , corresponding to a blank equivalent to $0.17 \mathrm{pg}$ of normal $\mathrm{Re}$ from the filament. The run was continued at constant temperature until approximately $3 \%$ of the initially loaded Re tracer had been ionized and detected (determined by integration of the ion beam intensities over time). If a constant, but initially unknown, blank contribution to the measured ion beams is assumed, then the data from this experiment can be used to determine the magnitude of the blank contribution. This contribution corresponds to $\approx 5 \times 10^{3} \mathrm{cps}$ at mass 251 .

The Re blank contributions determined from these two experiments are in general agreement. It follows that for our current generation of "clean" Pt filaments, the background current, using $\mathrm{BaSO}_{4}$ as the emitter, corresponds to $10^{3}-10^{4} \mathrm{cps}$ at mass 251 . This low level of Re blank has broad applicability in Re-Os geochemical studies.

During analyses of seawater samples, the observed drift in the measured ratios led to a typical uncertainty in these ratios of less than $\pm 1.5 \% \mathrm{amu}{ }^{-1}$, consistent with mass dependent isotope fractionation associated with sample depletion. No other drift was observed (e.g., as would be obtained from a variable filament blank), even when beam intensities were increased by an order of magnitude under different operating conditions. Replicate analyses of samples at $6 \mathrm{~m}, 402 \mathrm{~m}$, and $2800 \mathrm{~m}$ were in agreement to $\pm 3 \%$ (Table 1), consistent with this source of uncertainty. The close agreement of the two $2800 \mathrm{~m}$ fractions, spiked with different tracer solutions, indicates that the calibrations of the Dil-1 and Dil-2 tracer solutions are well within the analytical uncertainties.

An uncertainty propagation calculation was made for each sample, including the uncertainties in all gravimetric measurements, as well as the uncertainties in the concentration and isotopic composition of the Re tracer solution, and the uncertainty in the isotopic composition of natural Re. An uncertainty of $\pm 3 \%$ was assigned to the measured isotopic ratio of each spiked sample, due to the mass-fractionation uncertainty discussed above. An uncertainty of $\pm 50 \%$ was assigned to the $3 \mathrm{pg}$ chemical blank. The cumulative uncertainties from these sources (at $95 \%$ confidence) are reported in Table 1, and 


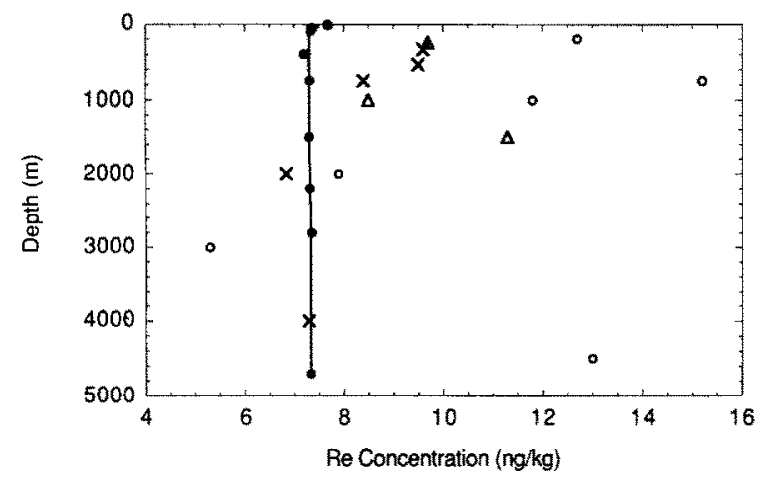

FIG. 1. The concentration of Re at various depths in the Pacific Ocean. The solid circles are data from this study; other points are from KotDE et al. (1987). Our samples were taken at $22^{\circ} \mathrm{N} 158^{\circ} \mathrm{W}$. Other samples were taken at $33^{\circ} \mathrm{N} 139^{\circ} \mathrm{W}$ (open circles); $35^{\circ} \mathrm{N}$ $122^{\circ} \mathrm{W}$ (triangles), and $35^{\circ} \mathrm{N} 138^{\circ} \mathrm{W}$ (crosses).

were typically within $\pm 5 \%$. This is consistent with mass fractionation as the primary source of uncertainty for most samples.

\section{RESULTS AND DISCUSSION}

The results are shown in Table 1. The Re concentrations are presented both as direct determinations, and on a salinitynormalized basis ( normalized $\operatorname{Re}, \operatorname{Re}_{\mathrm{N}}=\operatorname{Re}_{\text {semple }} \times 35 / \mathrm{sam}$ ple salinity). A comparison of the depth profile determined in this study with the Pacific Ocean profiles of KoIDE et al. (1987) is shown in Fig. 1. In contrast to the previous studies, our data clearly demonstrate that the concentration of $R e$ is essentially constant with depth, and that the chemistry of Re is generally conservative, as was predicted on thermodynamic grounds (BRULAND, 1983; BROOKINS, 1986). This result is consistent with less precise recent measurements using isotope dilution-inductively coupled plasma mass spectrometry (ICP-MS), which yield marine profiles that are uniform with depth to within $\pm 4 \%$ (COLODNER, 1991).

The consistency of our data is a significant improvement over the previous measurements of Re in seawater. Our best estimate of the average Re concentration of seawater is 7.31 $\pm 0.11 \mathrm{ng} / \mathrm{kg}$, or $7.42 \pm 0.04 \mathrm{ng} / \mathrm{kg}$ on a salinity-normalized basis. These values were obtained by averaging all the data below $400 \mathrm{~m}$, where the salinity-normalized $\operatorname{Re}$ concentrations are most uniform. The uncertainties are $\pm 2 \sigma$ of the data used to calculate the averages. The samples from depths shallower than $400 \mathrm{~m}$ appear to deviate somewhat from conservative behavior, but it is not clear whether these deviations represent actual variations in the concentration of $R e$ in the water column (see the following text and Fig. 2). Thus, these measurements are omitted from the best estimate. Table 2 compares our best estimate of the concentration of $R e$ in seawater with the corresponding estimates from other studies. Our determination is within the wide range of the analyses of SCADDEN (1969), MatTHEWS and Riley (1970), and KOIDE et al. (1987), but is substantially higher than the value from the Atlantic Ocean study of OLAFSSON and RILEY (1972). As suggested by KoIDE et al. (1987), we suspect that the uncertainties in these earlier studies are due, in large part, to variability in the yields of the chemical separation of $R e$ from seawater. A systematically low yield could also explain the shift between our average value and that of OLAFSSON and RILEY (1972). Since, in our isotope dilution analyses, the tracer was added prior to chemical separation, yield uncertainties were not a source of error, as long as the sample and tracer isotopes equilibrated. The reproducibility of our data provide support that this was the case.

Our average seawater value is significantly lower than the best estimate by COLODNER (1991) of $8.19 \pm 0.37 \mathrm{ng} / \mathrm{kg}$,
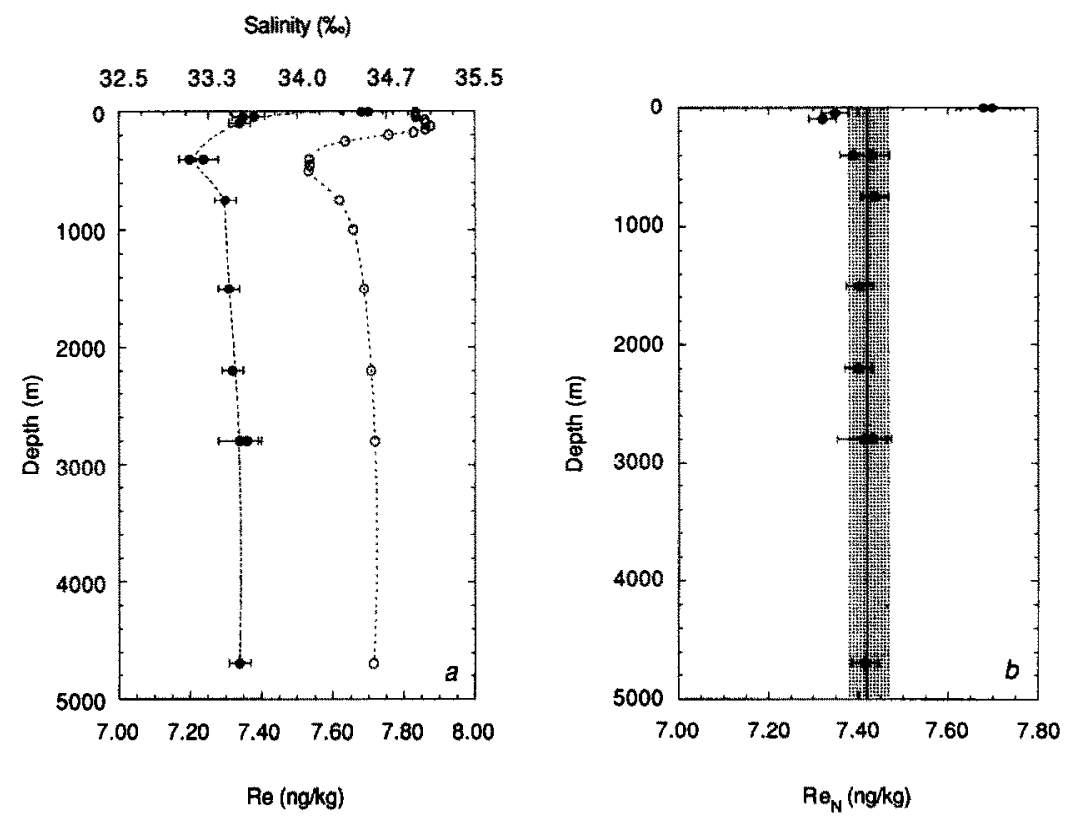

FIG. 2. (a) Depth profiles of salinity (open circles) and Re (solid circles) measured in this study. (b) Depth profile of $\mathrm{Re}$ normalized to $35 \%$ salinity. The vertical line represents the average Re concentration of the samples below 400 $\mathrm{m}(7.42 \mathrm{ng} / \mathrm{kg})$, and the shaded area denotes the $95 \%$ confidence limits of this value $( \pm 0.04 \mathrm{ng} / \mathrm{kg})$. 
TABLE 2. Estimates of the average Re concentration in seawater

\begin{tabular}{|c|c|c|}
\hline Location & $\mathrm{Re}$ (ng/ka) & Reference \\
\hline Pacific Ocean & $7.42 \pm 0.04$ & (a) This study \\
\hline Pacific Ocean & $9.1 \pm 4.4$ & (b) Koide et al., 1987 \\
\hline Pacific Ocean & $8.4 \pm 2.4$ & (c) Scadden, 1969 \\
\hline Atlantic Ocean & $4.0 \pm 2.1$ & (d) Olafsson and Riley, 1972 \\
\hline Atlantic Ocean & $6.9 \pm 2.1$ & (e) Matthews and Riley, 1970 \\
\hline Average Ocean & $8.19 \pm 0.37$ & (f) Colodner (1991) \\
\hline
\end{tabular}

Depth profiles were measured in all studies except (c), which included only surface samples. In (b) and $(e)$, no data at depths shallower than $200 \mathrm{~m}$ were obtained. Studies (b), (c), (d) and ( $f$ included samples from more than one location. Uncertainties in (b) (c) and (f) were reported by the authors as $\pm 1 \sigma$ of the measurements, but have been converted to $\pm 2 \sigma$ for comparison with this study. No uncertainty estimates were included in (d) and (e); by analogy to (b) and (c), we have calculated their uncertainties as $\pm 2 \sigma$. Our average, (a), includes all measurements below 400 $m$, and the uncertainty is reported as $\pm 2 \sigma$ of these values. Average values from studies (a) and (f) are reported on a salinitynormalized basis.

reported on a salinity normalized basis with $2 \sigma$ uncertainty. There appears to be a systematic offset between our data and those of COLODNER (1991). This discrepancy may in part be due to the fact that the results of this study are based on filtered seawater samples, as compared to the unfiltered samples used by COLODNER (1991). For example, KRISHNASWAMI et al. (1981) and CochRAN et al. $(1983,1990)$ have shown that a significant fraction of the ${ }^{210} \mathrm{~Pb}$ in seawater is bound to particles. This is true for many trace elements (e.g., BRULAND, 1983; WHITFIELD and TURNER, 1987). However, if this mechanism alone were to account for the discrepancy between the data sets, it would indicate a much greater reactivity of $\operatorname{Re}$ than is implied by the general uniformity of $\operatorname{Re}$ concentrations with depth. Further work is needed to determine the source of the discrepancy, and whether differences in acidification or storage procedures are important.

It should be noted that some of the previous studies included data from several locations (see Table 2). Thus, some of their variability could have been due to real geographical variations in the $R e$ content of seawater. We believe such variability is unlikely, however, due to the apparently conservative behavior of $\mathrm{Re}$, as illustrated in Fig. 1, and because, for the less precise earlier work, there appears to be as much variability within a depth profile at one location as there is between samples collected at different sites (see, especially, KOIDE et al., 1987).

The precision of our data allows detail in the Re profile to be resolved for the first time. The Re concentration decreases from a value of $7.34 \pm 0.04 \mathrm{ng} / \mathrm{kg}$ at $4705 \mathrm{~m}$ to an average value of $7.22 \pm 0.04$ at $402 \mathrm{~m}$, and then rises to an average of $7.69 \pm 0.07$ at $6 \mathrm{~m}$ (Fig. 2a). The decrease in the $\mathrm{Re}$ concentration between 4705 and $402 \mathrm{~m}$ is comparable to the percent decrease in salinity over the same depth range ( $\approx 1.5 \%$ ), which is consistent with conservative behavior. However, at $100 \mathrm{~m}$, the $\mathrm{Re}$ concentration does not exceed the deep-water value, although there is a pronounced salinity maximum at this depth. A good corrclation with salinity should be reflected in a $\operatorname{Re}$ concentration of $\approx 7.4 \mathrm{ng} / \mathrm{kg}$ at $100 \mathrm{~m}$ (Fig. 2b). Although the sampling was not ideally spaced at these depths, this predicted value is nearly 1.0$1.5 \%$ higher than the average of the measured values at 100 $\mathrm{m}$, and, therefore, should be detectable well within our analytical uncertainty. The salinity-normalized data suggest that the $51 \mathrm{~m}$ sample may also be somewhat depleted in Re relative to the deep waters, although this variation is within the uncertainties of the measurements. The surface enrichment is reflected only in the $6 \mathrm{~m}$ sample, and persists in the salinitynormalized data. The measured Re concentration at the surface is $\approx 4 \%$ higher than the average of the other samples, which is well above the analytical uncertainties.

These observations suggest that while the behavior of $\operatorname{Re}$ is essentially conservative, its distribution may be modified by two types of processes. The first process is a slight depletion due to biological or inorganic scavenging near the surface, and subsequent regeneration at depth; this mechanism could account for the apparent depletion at $100 \mathrm{~m}$. The second process is an input of possibly anthropogenic $R e$ to the ocean surface, probably via the atmosphere, which could be reflected in the surface Re enrichment. This mechanism is analogous to that observed for lead (SCHAULE and PATTERSON, 1981).

The interpretation of small variations in the $R e$ concentration calls for caution, however, due to potential problems of $\operatorname{Re}$ contamination during sample collection, or removal of dissolved Re from solution during sample storage. Although the possibility of contamination cannot be ruled out, particularly for samples from shallow depths, the fact that the samples from 45 and $51 \mathrm{~m}$ are identical within errors, despite being collected using different types of sampling equipment, indicates that there was little or no Re contamination from the sampling procedure itself. As for Re removal during storage, it is possible that a small, but detectable, quantity of $\operatorname{Re}$ was lost due to adsorption on the walls of the polyethylene bottles, or reduction of $\mathrm{ReO}_{4}^{-}$following addition of $\mathrm{HCl}$ to these samples (COTTON and WILKINSON, 1988). This interpretation would demand that a nearly constant amount of $\mathrm{Re}$ was lost from most of the samples, to account for the uniformity of the salinity-normalized values below $402 \mathrm{~m}$. Although this seems unlikely, it could account for the apparent enrichment of the $6 \mathrm{~m}$ sample, which was spiked aboard ship soon after sample collection, as well as the nonconservative behavior of the $100 \mathrm{~m}$ sample. Clearly, further work is needed to ascertain the importance of such sample collection and storage processes before these data are interpreted to the limits of the analytical precision.

These problems notwithstanding, our data confirm that $\mathrm{Re}$ is among the more conservative of elements in seawater, as exemplified by its relatively constant concentration with depth. These results also demonstrate that the refined chemical techniques described above, coupled to the ID-NTIMS technique, have the potential to improve substantially our understanding of the geochemistry of trace elements previously studied only with difficulty. We are currently extending this approach to the study of several platinum group elements in seawater.

Acknowledgments - The authors are grateful to D. Karl, R. Lukas, C. Winn, D. Hebel, and the captain and crew of the R/V Wecoma for assistance in sample collection and analysis. $D$. Karl and R. Lukas 
kindly provided unpublished data from the HOT-33 cruise. We appreciate the helpful comments of $\mathrm{K}$. K. Turekian and a second, anonymous reviewer. This work has been supported by NASA grant NAG 9-43 and NSF grant OCE 9018534. Ship time on the R/V Wecoma was supported by NSF grants OCE-8800329 (D. Karl) and OCE-8717195 (R. Lukas). Division contribution No. 5159 (777).

\section{Editorial handling: G. Faure}

\section{REFERENCES}

Brookins D. G. (1986) Rhenium as analog for fissiogenic technetium: Eh-pH diagram $\left(25^{\circ} \mathrm{C}, 1\right.$ bar) constraints. Appl. Geochem. 1, 513-517.

BRULAND K. W. (1983) Trace elements in sea-water. In Chemical Oceanography, Vol. 8 (ed. J. P. RILEY and R. CHESTER), Chap. 45 , pp. 157-220. Academic Press.

COCHRAN J. K., BACON M. P., KRISHNASWAMI S., and TUREKIAN K. K. $(1983)^{210} \mathrm{Po}$ and ${ }^{210} \mathrm{~Pb}$ distributions in the central and eastern Indian Ocean. Earth Planet. Sci. Lett. 65, 433-452.

Cochran J. K., MCKibBin-VaughN T., Dornblaser M. M., HiRSCHBERG D., LiVingston H. D., and BUESSELER D. (1990) ${ }^{210} \mathrm{~Pb}$ scavenging in the North Atlantic and North Pacific Oceans. Earth Planet. Sci. Lett. 97, 332-352.

COLODNER D. (1991) The marine geochemistry of rhenium, iridium, and platinum. Ph.D. thesis, MIT/WHOI, WHOI-91-30.

CoTron F. A. and WILKINSON G. (1988) Advanced Inorganic Chemistry, Sth ed. J. Wiley \& Sons.

Creaser R. A., Papanastassiou D. A., and Wasserburg G. J. (1991) Negative thermal ion mass spectrometry of osmium, rhenium, and iridium. Geochim. Cosmochim. Acta 55, 397-401.

DELMORE J. E. (1987) Rare-earth catalyzed oxidation of rhenium to $\mathrm{ReO}_{4}^{-}$and $\mathrm{ReO}_{3}^{-}$as observed by negative surface-ionization mass-spectrometry. J. Phys. Chem. 91, 2883-2886.

GOLDBERG E. D., KoIDE M., Y ANG J. S., and BERTINE K. K. (1986) Some comparative marine chemistries of platinum and iridium. Appl. Geochem. 1, 227-232.

GoldBerg E. D., KoIDE M., YANG J. S., and BeRTINE K. K. (1988) Comparative marine chemistries of platinum group metals and their periodic table neighbors. In Metal Speciation: Theory, Analysis and Application (ed. J. R. KRAMER and H. E. ALLEN), Chap. 10, pp. 201-217. Lewis Publishers.

Gramlich J. W., Murphy T. J., Garner E. L., and Shields
W. R. (1973) Absolute isotopic abundance ratio and atomic weight of a reference sample of rhenium. Nat. Bur. Stds. J. Res. 77A, 691-698.

HEUMANN K. G. (1988) Isotope dilution mass spectrometry. In Inorganic Mass Spectrometry (ed. F. ADAMS et al.), Chap. 7, pp. 301-376. J. Wiley \& Sons.

HuffMan E. H., Oswalt R. L., and Williams L. A. (1956) Anionexchange separation of molybdenum and technetium and of tungsten and rhenium. J. Inorg. Nucl. Chem. 3, 49-53.

JACINTO G. S. and YAN DEN BERG C. M. G. (1989) Different behavior of platinum in the Indian and Pacific Oceans. Nature 338, 332334.

KARL D. M. and WINN C. D. (1991) A sea of change: Monitoring the oceans' carbon cycle. Environ. Sci. Technol. 25, 1976-1981.

KoIDe M., Hodge V., Yang J. S., and Goldberg E, D. (1987) Determination of rhenium in marine waters and sediments by graphite furnace atomic absorption spectrometry. Anal. Chem. 59, 1802-1805.

KRISHNaSWAMI S., SARIN M. M., and Somayajulu B. L. K. (1981) Chemical and radiochemical investigations of surface and deep particles of the Indian Ocean. Earth Planet. Sci. Lett. 54, 81-96.

LEE D. S. (1983) Palladium and nickel in north-east Pacific waters. Nature 305, 47-48.

Matthews A. D. and RILEY J. P. (1970) The determination of rhenium in seawater. Analyt. Chim. Acta 51, 455-462.

OLAFSSON J. and RILEY J. P. (1972) Some data on the marine geochemistry of thenium. Chem. Geol. 9, 227-230.

SCADDEN E. M. (1969) Rhenium: Its concentration in Pacific Ocean surface waters. Geochim. Cosmochim. Acta 33, 633-637.

SCHAUle B. K, and PATTERSON C. C. (1981) Lead concentrations in the northeast Pacific: Evidence for global anthropopgenic perturbations. Earth Planet. Sci. Lett. 54, 97-116.

VOLKENING J., WALCZYK T., and HeUMANN K. G. (1991) Osmium isotope ratio determinations by negative thermal ionization mass spectrometry. Intl. J. Mass Spectrom. Ion Proc. 105, 147-159.

Wasserburg G. J., Papanastassiou D. A., Nenow E. V., and BAUMAN C. A. (1969) A programmable magnetic field mass spectrometer with on-line data processing. Rev. Sci. Instrum. 40, 288295

WHITFIELD M. and TURNER D. R. (1987) The role of particles in regulating the composition of sea water. In Aquatic Surface Chemistry (ed. W. STUMM), pp. 457-493. J. Wiley \& Sons.

ZEININGER H. (1984) Ph.D. thesis, University of Regensburg. 